\title{
Wider Perspective on Economical Management and Areas of Improvisation of Non-Major Indian Ports
}

\author{
R.U.Nagaraja \\ Associate Business Analyst, Exemplarr Worldwide, 141, Rajiv Gandhi Salai, OMR Kottivakkam, Chennai -41
}

\begin{abstract}
The entire functionality of the enterprise can be understood by mapping the process of the enterprise. The main objective of business process improvement and process mapping is to reduce the operational delay and to keep a check on the process. There are many references to business process improvement. The references had stressed the benefits of business process improvement in general which is common to all the industry. Business Process Improvement and ways to improve the business process from port domain perspective had received a little or no attention. This paper aims to uncover areas or departments where process can be improved in non-major ports handling small quantity of cargo every month.
\end{abstract}

\section{Introduction}

Rapid increase in the world trade in the past decade has contributed to greater demand for international transport and logistics. Greater demand for international transport has led to the expansion of the maritime industry. The dramatic changes in the mode of world trade and cargo transportation make it more important now than ever to have a clear understanding of the way in which freight is transported by sea and the role of ports in this exchange. A lot of ports are coming up everywhere around the globe. The importance of port management in the present century and its ability to cope up with the change over the last century has been highlighted in the book "Port Management" written by Patrick.M.Alderton. Competition among various ports around the world in attracting the customers has led to privatization of ports. De Langen (2007)and Ugboma et al. (2006) have identified customer focus as one of the most important factor considered by shippers in port selection. Privatization is not a new word. Privatization had already taken place in many industries like air industry, oil industry etc., The main objective of privatization is to achieve the operational efficiency. Ports play a major role in determining country's competiveness and economic health. One way of improving the operational efficiency is to improve/re-engineer the system or process involved in carrying out the daily port operations. Process Improvement not only increases the operational efficiency but also highlights the loop holes involved in a particular process and cuts down unwanted expenses related to the port operations which ultimately leads to profit maximization.

\section{Business Process Improvement}

Two major classifications of ports are major port and non-major port. Major Port can collectively handle 400+million tons of cargo annually as far as India is concerned. Non-Major Port can handle less than 10 lakh tons per month. There is another classification called medium sized port which we are not concerned about. Major Port invests more money on infrastructure to handle many vessels at a time. Moreover the process/system involved in the daily operations of major port will be simple and not complicated as mechanization and technology plays a major role in the daily operational process. Simpler the process lesser is the operational delay. Non-Major Port on the other hand does not invest money on infrastructure. Poor infrastructure will lead to operational delay. But operational delay can be minimized to a great extent with process improvement and process re-engineering.

Ports strive hard to maximize the profit by putting pressure on business development team or spending more on marketing. But profit maximization could also be achieved if present process/system which is not transparent or complicated could be rectified and by improving the operational efficiency. Operational efficiency could lead to client satisfaction. Client satisfaction will lead to profit maximization. Operational delay may be due to improper planning or due to flaws in the process. Lynn A Corson in his research manual "Manual of Best Management Practices for Port Operations" noted the importance of best management practices for improving the operational efficiency.

First step in business process improvement is to understand the processes involved in the daily operations. After understanding the operations process mapping has to be carried out. Once the process is mapped, the most important job is to find the flaws in the process. The process should be improved or reengineered if there are any flaws in the process or if the process itself is complicated. Mentioned below are the ways to understand the process 
Wider Perspective on Economical Management and Areas of Improvisation of Non-Major Indian

\section{A. Live Data Collection}

Collecting data on live helps to understand the process better. Complexity of the process can be understood with live data collection. Live data collection involves preparing new templates to capture the daily operations.

\section{B. Observation}

Process can be understood better by observing the operations from the field. The reasons for the operational delay will also be known by observing the operations on field.

\section{Interview}

The most common way of understanding the process is to conduct an informal interview with the head of different departments involved in the daily operations.

The main aim of the port is to achieve the operational efficiency with the available resources. In other words, the cargo should reach the client's place at the right time; this leads to client's satisfaction. The most important and challenging job of the port is to retain the existing customer and gaining new customers as a consequence of positive effect of word of mouth. It costs more to attract new customers than retain the existing ones. Process Mapping helps to record every operation regarding distance and time. It helps to identify the unwanted actions and documents the process completely. Inefficient port operations results in increased terminal charges. Foster (1978) had suggested the benefits of decreased terminal charges as one of the important criteria of port selection. Any increase in the port charges reflects an image of poor port performance. This also affects the shipping operators. They need to introduce more ships in a trade route to make up for possible disruptions caused by port inefficiency. Mentioned below are the areas where process improvement or process reengineering can be done as far as non-major ports are concerned.

\section{Plot Management}

Unloaded cargo from the vessel will be dumped in the plot. Cargo catches fire if not dumped properly which affects the quality of cargo. The perception of cargo safety is more important than actual safety (De Este and Meyrick, 1992). Perception of cargo quality and safety influences the users' choice of port. For tracking the vessel, name boards should be kept in front of each vessel's cargo heap. Plots should be divided into sub plots and numbering should be given to those sub plots. This aids in vessel cargo tracking. Cargo should be dumped in the sub plot which will avoid confusion while taking out the cargo to the client place. This will also avoid mixing of different vessel heaps. The main aim of plot management is to allocate space for the clients considering mode of dispatch. The dispatch will be either through road or rake. If the dispatch for a particular client is more through rake, then it is wise to dump the cargo in the sub plots nearer to the railway siding. The idea is to minimize the time while moving the cargo from berth to plot and from plot to railway siding. UNCTAD (1992) cited "on timely delivery" as one of the reasons for the shippers for port selection. On the other hand, if a dispatch for a client is more through road, then it is better to dump the cargo near the exit gate. Plot Management Application is a part of plot management. The advantages of plot management application are

- It records cargo inflow and out flow accurately

- Provides information about the sub plot at any given point of time

- Cargo shipments are recorded and can be accessed at any time

- Dwell time of cargo at the port can be accessed

- $3 \mathrm{~d}$ view of cargo heaps for the clients

\section{Road Infrastructure}

Good infrastructure leads to high level of productivity and efficiency (Sanchez et al. 2003). Roads should be properly laid. Equipments and tippers are involved in cargo evacuation and cargo dumping. Tippers will be used to move the cargo from one place to another place inside the port premises. The rate of breakdown of tippers increases if roads are not well laid. To bring the tipper from breakdown status to working status money is spent to buy the spare parts, which in turn eats the profit. The daily operations will be affected if more number of tippers is in breakdown state. At the same time operational efficiency is also affected with the less number of tippers. The management should also make sure that the roads are wide enough to accommodate more than 2 tippers at a time. Cargo spillage will be less if the roads are wide. Time spent on clearing the cargo spillage should be avoided to the maximum extent possible. Tippers and equipments will be involved in clearing the spilled cargo which is an unwanted wastage of fuel. This fuel wastage will eat the profit of the port. Road should be named or numbered to avoid confusion during cargo evacuation and cargo dumping. Speed guns should be installed on the roads to monitor the speed of the tippers. The main aim is to avoid accident and spillage of cargo. Port layout should also be installed to avoid confusion among the drivers of the trucks during 
road dispatch. Drivers should be educated to follow a proper route during cargo dumping and cargo evacuation to avoid traffic congestion and accidents.

\section{Cargo Wetting}

Non-Major Ports that handle cargoes like coal, petcoke and ironore pillets should ensure that environment is not affected during cargo dumping and cargo evacuation. Management is worried about in bringing more vessels to the port. But less importance is given to cargo management. All the roads and the vessel heaps should be watered regularly to avoid environmental pollution. Cargo like coal catches fire easily if not watered regularly which will affect the quality of the cargo. Cargo loss will be more during heavy storm and windy condition if vessel heaps are not wet. From management perspective profit is more important but whereas from client perspective the cargo quantity is most important. So, to maintain and manage the cargo properly, wetting of cargo should be done on a regular basis. Equipments like truck mounted road sweeping machine, mist sprayer and dust suppression system can be employed to reduce the pollution level and to minimize the cargo loss. Tongzon (1995) had cited that clients are ready to invest more on import and export but without compromising on the quality of service. Client retention is not possible if cargo loss is more. They may switch over to other ports if they are dissatisfied with the quality of service. Hydrants which are used to wet the cargo plays a major role in reducing the pollution level. Port Authorities must take steps to educate the workers to handle the hydrants with utmost care. Separate tools for handling the hydrants should be provided to the workers to avoid the damage of hydrants. Hydrant Marker can be placed on the top of the hydrants to avoid damage of hydrants by the equipments or tippers during night time due to poor visibility. The damage of hydrants leads to operational delay and money is also involved in repairing the damaged hydrants which eats away the profit of the port. Environment department must install hydrants at the places where chances of pollution level are high. Equipments and tippers should not pass on the hose connected to the hydrants as likelihood of damage of the hose is high. A hose of 30 meters length costs about 8000 - 10000 rupees. Numbering of hydrants is necessary to easily track the status of hydrants whether they are in working condition or in non-working condition.

\section{Equipment and Tipper Requirement Planning}

Planning is important for achieving operational efficiency. Planning of tipper and equipment allocation should be done in advance to carry out the next day's operations. The main objective is to avoid confusion at the last minute and to reduce the vessel demurrage and rake demurrage due to operational delay. Difference between actual allocation and planned allocation should also be monitored for future analysis.

\section{Equipment and Tipper Utilization}

Most of the equipments and tippers in the port for the daily operational activity will be on hire basis. A huge amount of money will be spent on to hire tippers and equipments on a monthly basis. Money has to be paid to the owners of the tippers and equipments even if the tippers and equipments are underutilized. Over utilization may lead to frequent breakdown. Frequent breakdown will lead to operational delay. Instead of over utilizing tippers and equipments, preventive maintenance and schedule maintenance has to be performed on tippers and equipments. Over utilization will damage the equipments and tippers to a great extent. High quality cargo handling equipments leads to high level of productivity (Sanchez et.al 2003). Replacing the damaged tippers or equipments with new ones consumes time which will affect the operational efficiency. Huge amount of money is also spent to replace or buy new tippers or equipments. Optimum utilization of tippers and equipments is necessary for achieving maximum efficiency.

\section{Cost Cutting}

Expenses incurred for each and every department should be monitored and analyzed. The vision of the port is to maximize the profit by bringing more vessels to the port and to reduce the unwanted expenses both of which will affect the cost incurred for the port to handle 1 metric ton of cargo. Cutting unwanted expenses will reduce the cost incurred for the port to handle 1 metric ton of cargo to a great extent. Electricity plays a major role in increasing the expenses of the port. Lights can be switched off if there are no operations taking place in a particular area. All the departments should analyze their monthly expenses and take steps to cut down the unwanted expenses which will contribute to the port's profit.

\section{Fuel Audit}

The most important area which consumes the profit of the port is the equipment fuel and tipper fuel. Mileage rate for all the equipments and tippers should be monitored. Poor performing tippers and equipments in terms of fuel consumption should be replaced with new ones. There are chances of fuel theft from the equipments and tippers. Random check should be done on equipments and tippers every day by noting down the hour meter reading and kilo meter reading. This will minimize the fuel theft as most of the equipment drivers 
and tipper drivers will be manipulating the hour meter and kilo meter readings. Indent will be raised when fuel is filled for an equipment or tipper during working condition. There are chances when indent may not be raised when an equipment or tipper is in breakdown state or maintenance state. Mechanical department should be advised to raise the indent while filling the fuel for equipments or tippers during maintenance or breakdown state. This will control the selling of fuel from equipments or tippers.

\section{Departmental Audit}

Audit has to be conducted for all the departments in the port on random basis. Most of the employees working in the port will be hired on contract basis. Contractors would have promised to employ $\mathrm{x}$ workers as per the contract but in real scenario less than $\mathrm{x}$ workers will be working for a particular operation. But the port is paying for $\mathrm{x}$ workers. This will affect the profit as well as operational efficiency. The main objective of departmental audit is to check whether the daily activities or operations are carried out by the contractors properly and regularly. Another important objective of departmental audit is to check whether the contractors are fully equipped to carry out the daily operations. In some cases port has to provide the equipments and tools for the daily operations but in most of the cases contractors must be fully equipped and they should take care of tools and equipments to carry out the daily operations.

\section{Asset Utilization}

There will be a lot of assets in the port which will be under utilized for a long period of time. Even though they are underutilized, monthly hire charges has to be paid for those assets. Asset could be a fertilizer packing machine or shore cranes. In some cases these assets will not be utilized at all for a longer period. The monthly hire charges for cranes and packing machines will be very high. Paying money from the port's pocket for these assets which will not improve the operational efficiency is an unwanted expense which will hugely affect the profit of the port.

\section{Scrap Management}

In most of the ports, less importance is given to scrap management. Unlike waste, scrap can have significant monetary benefit. All the scraps lying around the port should be collected and managed at a single place. The port authorities will have an account of all the scraps lying in the port if the scraps are managed properly. This will avoid theft and minimize accidents or injury due to improper scrap management.

\section{Equipment Deployment Cell}

An equipment deployment cell can be formed to monitor the equipment status. The primary objective of the cell is to come up with equipment and tipper performance analysis on a monthly basis. The members of the cell should note down the opening kilo meter reading and closing kilo meter reading for the equipments and tippers. This will avoid manipulation of readings by the drivers of tippers and equipments. The members of the cell can also cross verify their data with the data provided by the contractors or third party logistics providers. Hesse and Rodrigue (2004) have underlined the importance and growth of third party logistics providers. The members of the cell can also identify frequently repeated causes for breakdown of equipments and tippers, number of days a particular equipment or tipper is in breakdown state and its breakdown repetition. This data will be helpful for the mechanical department to maintain spare parts for frequently repeated breakdowns. An equipment or tipper in breakdown state can be brought to working state in a short period of time if spare parts are readily available; else equipments or tippers will be in breakdown state until spare parts are received from the vendor. Greater the breakdown period higher the operational delay. Port users are concerned with indirect costs associated with delays (Tongzon, 1995). The cell should also make sure that all the equipments and tippers belonging to different contractors are utilized properly and efficiently. All the contractors should be given a fair chance, provided the performance of tippers and equipments of a particular contractor is good.

\section{Reviewing the Contracts}

Contracts should be beneficial to the port. Any contract which is consuming the profit of the port should be taken seriously and reviewed again. There may be contracts where tippers are paid based on hourly basis not on trip basis. This kind of contract will affect the profit of the port and operational efficiency. If payment is based on hour basis the tipper drivers will not make extra efforts to make additional trips as payment is made on hourly basis. More the number of trips more the tonnage handled or more the tonnage intercarted from one place to another. The most important factor to be considered is the working pattern of tipper and equipment drivers. Tipper drivers will work for 24 hours continuously. This working pattern will lead to operational inefficiency. Tipper drivers should be allowed to work only for 12 hours continuously. If they work for 24 hours at a stretch they will be tired and this would decrease their efficiency about which the drivers are not worried as payment is based on hour basis and not on trip basis. 


\section{Technology}

Technology is used to check the process. Applications like Document Management System and Management Information System will be useful for the top management to take important decisions. A lot of manual work can be avoided with the incorporation of technology. Technological advancements in the port saves time and helps to improve the operational efficiency. Weighbridge plays a major role during dispatch of cargo to the client place. There will be more than one weighbridge in most of the ports. All the weighbridges should be integrated. A truck which passes by a weighbridge to capture tare weight should pass by the same weigh bridge to capture gross weight and net weight if the weighbridges are not integrated. This results in weighbridge congestion and may result in increase in turnaround time at the weighbridge. Malchow and Kanafani (2004) had suggested time as one of the major criteria of port selection. Moreover weighbridges should be accurate. Even small amount of cargo loss will have great impact on the profit of the port. Employees should be educated to use the applications or technology properly. They should be educated regarding the benefits of using the technology.

\section{Conclusion}

This paper has sought the importance of process improvement and process re-engineering to improve the port's performance and its efficiency. Efficiency will minimize the delay and leads to customer satisfaction. Customer satisfaction will maximize the profit. Three important parameters are related with business process improvement. They are customer satisfaction, profit maximization and operational efficiency.

\section{References}

[1]. Hesse, M., Rodrigue, J.P., 2004. The transport geography of logistics and freight distribution. Journal of Transport Geography

[2]. Sanchez, R.J., Hoffman, J., et al, 2003. Port efficiency and international trade: port efficiency as a determinant of maritime transport costs. Maritime Economics and Logistics

[3]. Abdul Karim Reengineering the Public Service, Pelanduk Publications

[4]. Ugboma, C., Ugboma, O., Ogwude, I., 2006. An Analytic Hierarchy Process (AHP) approach to port selection decisions - empirical evidence from Nigerian ports

[5]. Martin A Ould, Modelling and Analysis for Re-Engineering, Wiley

[6]. Hau L. Lee and SeungjinWhang, Higher Supply Chain Security with lower cost, Graduate School of Business

[7]. Richard Reed, Beyond Process: Tqm Content and Firm Performance, Washington State University

[8]. Tongzon, J., 1995. Determinants of port performance and efficiency

[9]. De Langen, P.W., 2007. Port competition and selection in contestable hinterlands: the case of Austria. European Journal of Transport and Infrastructure

[10]. Foster, T., 1978. What's important in a port? Distribution Worldwide

[11]. Malchow, M., Kanafani, A., 2004. Disaggregate analysis of port selection. Transportation Research

[12]. D'Este, G.M., Meyrick, S., 1992. Carrier selection in a RO/RO ferry trade, Maritime Policy and Management

[13]. UNCTAD, 1992. Strategic Planning for Port Authorities, United Nations, Geneva 